\title{
Managing a sustainable integrated inventory model for imperfect production process with type one and type two errors
}

Novrianty Rizky

Islamic University of Indonesia: Universitas Islam Indonesia

Ivan Darma Wangsa

Institut Teknologi Sepuluh Nopember

Wakhid Ahmad Jauhari

Sebelas Maret University: Universitas Sebelas Maret

Hui Ming Wee ( $\nabla$ weehm@cycu.edu.tw)

Chung Yuan Christian University https://orcid.org/0000-0002-2935-9506

\section{Research Article}

Keywords: Inventory, sustainable integrated model, type I and type II errors, crashing lead time, setup cost reduction

Posted Date: February 23rd, 2021

DOl: https://doi.org/10.21203/rs.3.rs-166796/v1

License: (9) This work is licensed under a Creative Commons Attribution 4.0 International License. Read Full License 


\title{
Managing a sustainable integrated inventory model for imperfect production process with type one and type two errors
}

\author{
Novrianty Rizky ${ }^{1}$ \\ ${ }^{1}$ Faculty of Industrial Technology, Department of Industrial Engineering, Universitas Islam Indonesia, \\ Yogyakarta, 55584, Indonesia \\ Email: 19916028@students.uii.ac.id \\ Ivan Darma Wangsa ${ }^{2}$ \\ ${ }^{2}$ Department of Industrial Engineering, Institut Teknologi Sepuluh Nopember, Surabaya, Indonesia, \\ Kampus ITS, Sukolilo, 60111, Indonesia \\ Email: ivan_darma@yahoo.com \\ Wakhid Ahmad Jauhari ${ }^{3}$ \\ ${ }^{3}$ Department of Industrial Engineering, Sebelas Maret University, Jl. Ir Sutami 36 A, Surakarta, 57126, \\ Indonesia, \\ Email: wachid_aj@yahoo.com

\section{Hui Ming Wee ${ }^{4 *}$} \\ ${ }^{4}$ Chair Professor, Department of Industrial and Systems Engineering, Chung Yuan Christian \\ University, No. 200, Chung Pei Road, Chungli, Taoyuan City, Taiwan 32023, ROC \\ Email: weehm@cycu.edu.tw
}

*Corresponding author: HM Wee

Tel.: +886-3-2654409; Fax: +886-3-2654499;

No. 200, Chung Pei Road, Chungli, Taoyuan City, Taiwan 32023, ROC

Email:weehm@cycu.edu.tw 


\title{
Managing a sustainable integrated inventory model for imperfect production process with type one and type two errors
}

\author{
This study develops a sustainable integrated inventory model for controllable lead time \\ with defective items, errors in inspection, and variable lead-time. The research \\ investigates the effect of controlling lead time and capital investment in the setup cost. \\ We assume that the buyer receives a lot size that may contain some defective items with \\ a known defective probability. The buyer's inspector conducts a $100 \%$ quality \\ inspection and may incorrectly classify a non-defective item as a defective item (type \\ one (I) error), or incorrectly classify a defective item as a non-defective item (type two \\ (II) error). The mathematical inventory model considering carbon emission cost is \\ developed, and the solution procedure is designed to derive the optimal solution. \\ Finally, numerical examples and sensitivity analysis are given to illustrate the results.
}

Keywords: Inventory; sustainable integrated model; type I and type II errors; crashing lead time; setup cost reduction

\section{Introduction}

In recent years, the issues of economics and sustainability in the supply chain have attracted considerable attention from governments, universities, and other non-profit organizations. Over the decades, many researchers have focused on extending the traditional inventory model to consider coordination mechanisms of the channel members, i.e., coordination between the vendor and buyer. Most of the traditional inventory models assume perfect production process and error-free inspection. However, in the most production processes, some defective items will be produced. To ensure good quality, the buyer conducts a $100 \%$ quality check for all goods received from the vendor. During the inspection, some of the good items may be rejected as defective items (type I error) while other defective items may be accepted as good items (type II error). The earliest research of the EOQ model with defective items was made by Salameh 
and Jaber (2000). They assumed a perfect inspection to screen out and dispose of the defective items. During the last two decades, other researchers have studied defective items under various conditions. They are Goyal and Cárdenas-Barrón (2002), Goyal et al. (2003), Wang (2005), Papachristos and Konstantaras (2006), Wee et al. (2007), Eroglu and Ozdemir (2007), Konstantaras et al. (2007), Maddah and Jaber (2008) and Khan et al. (2011). Hsu and Hsu (2012) have extended Khan et al. (2011)'s model by assuming the defective items in the inspection process are sold to a secondary market at a discounted price. Jauhari (2016) modified Khan et al. (2011)'s model by considering probabilistic demand. Jauhari et al. (2017) developed an unequal-sized shipment policy for a single-vendor and a single-buyer integrated inventory model with deterministic demand, defective items, and errors in the inspection. Khan et al. (2017) proposed a mathematical inventory model for a supply chain system with stochastic lead time. Jauhari et al. (2018) developed a two-echelon inventory model with stochastic demand, defective items, and carbon emissions cost. Tiwari et al. (2018a) proposed a vendor-buyer inventory model considering carbon emissions, deteriorating, and imperfect quality items. Tiwari et al. (2018b) investigated the impact of the investment of ordering and setup cost reduction and controllable lead time on the cost of the supply chain system. Wangsa and Wee (2019) developed an integrated inventory model considering freight cost and stochastic lead time. Recently, Tiwari et al. (2020) investigated the impact of human errors, variable lead time, and capital investment.

In this paper, we consider a joint optimization model with inspection errors, defective items, stochastic demand, controllable lead time, carbon emissions, and freight cost. The lead time demand follows a normal distribution, and the setup cost is a logarithmic function of capital investment. The objective of this study is to minimize the joint total cost (JTC) by optimizing the order quantity, lead time, safety factor, number of deliveries, setup cost. The research gaps are illustrated in Table 1. 
The rest of the paper is organized as follows. Section 2 provides the notation and assumptions. Section 3 develops the proposed mathematical model and algorithm to derive the optimal solution. Section 4 presents the numerical example and sensitivity analysis. Finally, the conclusions and future research directions are given in Section 5.

Table 1. Research Gap: comparison between the proposed model and previous models

\begin{tabular}{llccccc}
\hline Researcher(s) & Demand type & $\begin{array}{l}\text { Inspection } \\
\text { errors }\end{array}$ & $\begin{array}{c}\text { Crashing } \\
\text { lead time }\end{array}$ & $\begin{array}{l}\text { Setup cost } \\
\text { reduction }\end{array}$ & $\begin{array}{l}\text { Emission } \\
\text { carbon }\end{array}$ & $\begin{array}{l}\text { Freight } \\
\text { cost }\end{array}$ \\
\hline \hline Hsu and Hsu (2012) & Deterministic & $\sqrt{ }$ & - & - & - & - \\
Jauhari (2016) & Probabilistic & $\sqrt{ }$ & - & - & - & - \\
Jauhari et al. (2017) & Deterministic & $\sqrt{ }$ & - & - & - & - \\
Khan et al. (2017) & Probabilistic & $\sqrt{ }$ & - & - & - & - \\
Jauhari (2018) & Probabilistic & - & - & - & $\sqrt{ }$ & $\sqrt{ }$ \\
Tiwari et al. (2018a) & Deterministic & - & - & - & $\sqrt{ }$ & $\sqrt{ }$ \\
Tiwari et al. (2018b) & Probabilistic & - & $\sqrt{ }$ & $\sqrt{ }$ & - & - \\
Wangsa and Wee (2019) & Probabilistic & $\sqrt{ }$ & - & - & - & $\sqrt{ }$ \\
Tiwari et al. (2020) & Probabilistic & $\sqrt{ }$ & $\sqrt{ }$ & $\sqrt{ }$ & - & - \\
Proposed model & Probabilistic & $\sqrt{ }$ & $\sqrt{ }$ & $\sqrt{ }$ & $\sqrt{ }$ \\
\hline \hline
\end{tabular}

\section{Notations and assumptions}

\subsection{Notations}

The notations used to develop the model are listed below:

$Q \quad$ the size of shipments from the vendor to the buyer (decision variable)

$m \quad$ the number of deliveries (decision variable)

$k \quad$ safety factor (decision variable)

$S \quad$ setup cost per setup (decision variable)

$L \quad$ lead time (decision variable)

D average demand

$P \quad$ production rate of the vendor, $P>D$

$\sigma \quad$ standard deviation of demand

A $\quad$ ordering cost per order

$S_{0} \quad$ initial setup cost per setup

$h_{b} \quad$ buyer's holding cost per unit per year 
$h_{v} \quad$ vendor's holding cost per unit per year

$C_{S} \quad$ inspection cost per unit item

$x \quad$ inspection rate

$C_{w} \quad$ cost of producing defective item per unit item

$e_{1} \quad$ probability of Type I inspection error

$e_{2} \quad$ probability of Type II inspection error

$\gamma \quad$ probability of defective items (defect rate)

$B_{1} \quad$ defective items in each shipment size of $Q$

$B_{2} \quad$ returned items from market in each shipment size of $Q$

$C_{p b} \quad$ buyer's post-sales for each defective item

$C_{p v} \quad$ vendor's post-sales for each defective item

$C_{r} \quad$ cost of rejecting a good item

$\theta \quad$ additional cost for pick-up policy

$d_{v} \quad$ the vendor's distance to the freight

$d_{b} \quad$ the freight's distance to the buyer

$u \quad$ fuel consumption of a truck

w weight of product

$\alpha \quad$ discount factor for LTL shipments, $0 \leq \alpha \leq 1$

$F_{x} \quad$ cost of freight based on full truckload (FTL) in $\$$ per lb. per mile

$F_{y} \quad$ cost of freight based on less-than-truckload in $\$$ per lb. per mile

$W_{x} \quad$ full truckload (FTL) shipping weight in lbs.

$W_{y} \quad$ actual weight of shipping in lbs. $\left(W_{y} \leq W_{x}\right)$

$\pi \quad$ buyer's backorder cost per unit

$C_{g h g} \quad$ carbon emission cost

$\Delta_{b 1} \quad$ buyer's indirect emission factor 


$\begin{array}{ll}\Delta_{b 2} & \text { buyer's direct emission factor } \\ e_{c o} & \text { electricity energy consumption } \\ S_{c o} & \text { steam energy consumption } \\ h_{c o} & \text { heating energy consumption } \\ c_{c o} & \text { cooling energy consumption } \\ L_{r} & \text { energy loss rate } \\ \Delta_{v 1} & \text { vendor's indirect emission factor } \\ \Delta_{v 2} & \text { vendor's direct emission factor } \\ Y & \text { annual fractional cost of capital investment } \\ I(S) & \text { capital investment in setup cost reduction } \\ \xi & \text { the percentage decrease in } S \text { per dollar increase in } I(S) \\ c_{i} & \text { minimum duration of } i^{\text {th }} \text { lead-time component } \\ d_{i} & \text { normal duration of } i^{\text {th }} \text { lead-time component } \\ e_{i} & \text { crashing cost per days of } i^{\text {th }} \text { lead-time component } \\ J T C & \text { joint total cost }\end{array}$

\subsection{Assumptions}

The following assumptions are used to develop the model:

1. This research considers a single item with a single vendor and a single buyer.

2. The demand follows a normal distribution with mean $D$ and standard deviation $\sigma$.

3. The vendor manufactures a batch of $m Q$ units and ships $Q$ (units) to the buyer in each of the $m$ times. The setup cost $S$ is paid by the vendor for each production run and the ordering cost $A$ is paid by the buyer for each order of quantity $Q$.

4. The vendor produces the items with a finite production rate $P$ is higher than the demand rate $D$. 
5. The lead time $L$ consists of $n$ mutually independent components. For each $i^{\text {th }}$ component of lead time, $d_{i}$ is the normal duration, $c_{i}$ is the minimum duration, and $e_{i}$ is the crashing cost per unit time. We rearrange $e_{i}$ such that $e_{1} \leq e_{2} \leq \cdots e_{j}$.

6. The crashing cost is paid by the buyer if a shorter lead-time is requested.

7. The capital investment $I(S)$ in reducing the vendor's setup cost is a logarithmic function of the setup cost, $S$. That is, $I(S)=B \ln \left(\frac{S_{0}}{S}\right)$ for $0<S \leq S_{0}$ where $B=\frac{1}{\xi}$. (Tiwari et al., 2018b; 2020)

8. The vendor's production processes may produce defective items with the defective percentage $\gamma$ and probability density function of $f(\gamma)$. The lot received by the buyer is $100 \%$ quality check by the inspector with screening rate $x$. The screening rate is assumed to be greater than the demand rate, $x>D$.

9. The inspector may incorrectly classify non-defective items as defective $\left(e_{1}\right)$ with a probability density function of $f\left(e_{1}\right)$ and may incorrectly accept defective items as non-defective $\left(e_{2}\right)$ with a probability density function of $f\left(e_{2}\right)$.

10. The cost of producing defective item $\left(C_{w}\right)$ and the cost of rejecting a non-defective item $\left(C_{r}\right)$ are paid by the vendor.

11. Shortages are allowed and fully backordered.

12. The items will be scheduled to be picked up by the freight and delivered to the buyer's site. This cost (surcharge cost per shipment, $\theta$ ) is paid by the buyer for the pick-up.

13. The freight cost is paid by the buyer.

14. Defective items will be returned to the vendor at the end of the inspection process.

\section{Model development}


In this paper, we develop a sustainable integrated inventory under a vendor-buyer system taking into account the crashing lead time, defective items, inspection errors, freight cost, and investment for setup cost reduction. An equal-sized shipment policy is adopted by the system to deliver the items. The vendor produces a batch of items $(m Q)$ with a percentage of defective items. The vendor delivers the lot to the buyer over $m$ shipments.

The buyer's inspector screens out the defective items from the shipment lot with two types of mistakes: classifying good items as defective items $\left(e_{1}\right)$ and classifying defective items as good items $\left(e_{2}\right)$. The four possible cases may be found during an inspection process. They are:

- Case 1: classifying good items as defective items

- Case 2: classifying good items as good items

- Case 3: classifying defective items as good items

- Case 4: classifying defective items as defective items

Further, the development of the expected total cost for the buyer, expected total cost for the vendor, and the joint total expected cost are formulated in the following subsections.

\subsection{Expected total cost for the buyer}

In this section, we develop the buyer's initial expected cost $\left(T E C_{b 0}\right)$ considering ordering cost, surcharge cost, lead time crashing cost, shortage cost, inspection cost, type I and type II error cost, and holding cost. The buyer's initial expected cost is given by:

$$
\begin{aligned}
& T E C_{b 0}(Q, k, L, m)=\frac{D\left[A+\theta+R(L)+m \pi \sigma \sqrt{L} \psi(k)+m Q\left(C_{s}+C_{p b} \gamma e_{2}\right)\right]}{m Q(1-\gamma)\left(1-e_{1}\right)} \\
& +h_{b}\left\{\frac{D Q\left[(1-\gamma) e_{1}+\gamma\left(1-e_{2}\right)\right]}{x(1-\gamma)\left(1-e_{1}\right)}+\frac{Q\left[1-\left(e_{1}+\gamma\right)+\gamma\left(e_{1}+2 e_{2}\right)\right] \cdot(1-\gamma)\left(1-e_{1}\right)}{2(1-\gamma)\left(1-e_{1}\right)}+k \sigma \sqrt{L}\right\}
\end{aligned}
$$

The logistic provider offers pickup service at a freight cost rate $\left(F_{x}\right)$. Wangsa and Wee (2019) developed freight cost based on the actual shipping weight, $W_{y}=Q w(1-\gamma)\left(1-e_{1}\right)$. Therefore, the buyers expected freight cost is: 


$$
F C_{b}=\frac{D m \alpha F_{x} W_{x}\left(2 d_{V+} d_{b}\right)}{m Q(1-\gamma)\left(1-e_{1}\right)}+D(1-\alpha) F_{x} w\left(2 d_{V+} d_{b}\right)
$$

Furthermore, the buyer's carbon emission cost is divided into 2 categories, namely direct and indirect emissions. The carbon emission cost from Wangsa (2017) is given by:

$$
C E_{b}=D C_{g h g}\left[\frac{\Delta T_{1} u\left(2 d_{V+} d_{b}\right)}{m Q(1-\gamma)\left(1-e_{1}\right)}+\Delta T_{2} w\right]
$$

Combining the buyer's initial expected cost in Eq. (1), the freight cost in Eq. (2), and the carbon emission cost in Eq. (3), the buyer's expected total cost is:

$$
\begin{aligned}
& T E C_{b}(Q, k, L, m)=\frac{D\left[\begin{array}{c}
A+\theta+R(L)+m \pi \sigma \sqrt{L} \psi(k)+m Q\left(C_{s}+C_{p b} \gamma e_{2}\right) \\
+\left(m \alpha F_{x} W_{x}+C_{g h g} \Delta T_{1} u\right)\left(2 d_{V+} d_{b}\right)
\end{array}\right]}{m Q(1-\gamma)\left(1-e_{1}\right)} \\
& +h_{b}\left\{\frac{D Q\left[(1-\gamma) e_{1}+\gamma\left(1-e_{2}\right)\right]}{x(1-\gamma)\left(1-e_{1}\right)}+\frac{Q\left[1-\left(e_{1}+\gamma\right)+\gamma\left(e_{1}+2 e_{2}\right)\right] \cdot(1-\gamma)\left(1-e_{1}\right)}{2(1-\gamma)\left(1-e_{1}\right)}+k \sigma \sqrt{L}\right\} \\
& +D\left[(1-\alpha) F_{x} w\left(2 d_{V+} d_{b}\right)+C_{g h g} \Delta T_{2} w\right]
\end{aligned}
$$

\subsection{Expected total cost for the vendor}

The expected initial total cost for the vendor consists of setup cost, holding cost, rework cost for defective items, type I and type II error cost. The average inventory of vendor per cycle can be formulated as:

$$
I_{v}=\frac{\left[n Q\left(\frac{Q}{P}+(n-1) T\right)-\frac{n^{2} Q^{2}}{2 P}\right]-T[Q+2 Q+\cdots+(n-1) Q]}{n T}
$$

By substituting $T=\frac{Q(1-\gamma)\left(1-e_{1}\right)}{D}$ into Eq. (5) and simplifying the equation, one has:

$$
I_{v}=\frac{\left\{n Q\left[\frac{Q}{P}+(n-1) \frac{Q(1-\gamma)\left(1-e_{1}\right)}{D}\right]-\frac{n^{2} Q^{2}}{2 P}\right\}-T[Q+2 Q+\cdots+(n-1) Q]}{\frac{n Q(1-\gamma)\left(1-e_{1}\right)}{D}}
$$


$I_{v}=\left\{\frac{Q}{2}+\frac{(n-2) Q}{2}\left[1-\frac{D}{(1-\gamma)\left(1-e_{1}\right) P}\right]\right\}$

The vendor's initial expected total cost per unit time is:

$$
\begin{aligned}
T E C_{v}(Q, m)= & \frac{D\left\{S+m Q\left[C_{w} \gamma+C_{r}(1-\gamma) e_{1}+C_{p v} \gamma e_{2}\right]\right\}}{m Q(1-\gamma)\left(1-e_{1}\right)} \\
& +h_{v}\left\{\frac{Q}{2}+\frac{(m-2) Q}{2}\left[1-\frac{D}{(1-\gamma)\left(1-e_{1}\right) P}\right]\right\}
\end{aligned}
$$

The vendor's initial setup cost $(S)$ can be optimized by capital investment $I(S)$ which is a logarithmic function of the vendor's setup cost as follows:

$$
I(\mathrm{~S})=B \ln \left(\frac{S_{0}}{S}\right)
$$

where $0<S \leq S_{0}$; and $B=\frac{1}{\xi} ; \quad \xi$ is the percentage decrease in $S$ per dollar increase in $I(\mathrm{~S})$

If $Y$ is the vendor's fractional setup cost technology investment, then the formulation is:

$$
I S C_{v}=Y I(\mathrm{~S})=Y B \ln \left(\frac{S_{0}}{S}\right)
$$

The vendor's carbon emission cost equation is given by:

$$
C E_{v}=D C_{g h g}\left[\frac{\Delta V_{1}\left(e_{c o}+s_{c o}+h_{c o}+c_{c o}\right) L_{r} C_{g h g}}{m Q(1-\gamma)\left(1-e_{1}\right)}+D \Delta V_{2} C_{g h g}\right]
$$

From Eq. (8), Eq. (10), and Eq. (11), the vendor's expected total cost is:

$$
\begin{aligned}
T E C_{v}(Q, m, S)= & \frac{D\left\{\begin{array}{c}
S+m Q\left[C_{w} \gamma+C_{r}(1-\gamma) e_{1}+C_{p v} \gamma e_{2}\right] \\
+\Delta V_{1}\left(e_{c o}+s_{c o}+h_{c o}+c_{c o}\right) L_{r} C_{g h g}
\end{array}\right\}}{m Q(1-\gamma)\left(1-e_{1}\right)} \\
& +h_{v}\left\{\frac{Q}{2}+\frac{(m-2) Q}{2}\left[1-\frac{D}{(1-\gamma)\left(1-e_{1}\right) P}\right]\right\}+D \Delta V_{2} C_{g h g}+Y B \ln \left(\frac{S_{0}}{S}\right)
\end{aligned}
$$




\subsection{Joint total cost}

From Eq. (4) and Eq. (12), the joint total cost for the vendor-buyer system is:

$$
\begin{aligned}
& D\left\{\begin{array}{c}
A+S+\theta+R(L)+m \pi \sigma \sqrt{L} \psi(k) \\
+m Q\left\{\begin{array}{c}
\left.C_{s}+\gamma\left[e_{2}\left(C_{p b}+C_{p v}\right)+C_{w}\right]+C_{r}(1-\gamma) e_{1}\right\} \\
+\left(m \alpha F_{x} W_{x}+C_{g h g} \Delta T_{1} u\right)\left(2 d_{V+} d_{b}\right) \\
+\Delta V_{1}\left(e_{c o}+s_{c o}+h_{c o}+c_{c o}\right) L_{r} C_{g h g}
\end{array}\right\} \\
\operatorname{JTC}(1-\gamma)\left(1-e_{1}\right)
\end{array}\right. \\
& +h_{b}\left\{\frac{D Q\left[(1-\gamma) e_{1}+\gamma\left(1-e_{2}\right)\right]}{x(1-\gamma)\left(1-e_{1}\right)}+\frac{Q\left[1-\left(e_{1}+\gamma\right)+\gamma\left(e_{1}+2 e_{2}\right)\right] .(1-\gamma)\left(1-e_{1}\right)}{2(1-\gamma)\left(1-e_{1}\right)}+k \sigma \sqrt{L}\right\} \\
& +h_{v}\left\{\frac{Q}{2}+\frac{(m-2) Q}{2}\left[1-\frac{D}{(1-\gamma)\left(1-e_{1}\right) P}\right]\right\} \\
& +D\left[(1-\alpha) F_{x} w\left(2 d_{V+} d_{b}\right)+C_{g h g}\left(\Delta T_{2} w+\Delta V_{2}\right)\right]+Y B \ln \left(\frac{S_{0}}{S}\right)
\end{aligned}
$$

To simplify the equation, we denote:

$$
\begin{aligned}
& \bar{X}_{1}=(1-\gamma)\left(1-e_{1}\right) \\
& \bar{X}_{2}=(1-\gamma) e_{1}+\gamma\left(1-e_{2}\right) \\
& \bar{X}_{3}=1-\left(e_{1}+\gamma\right)+\gamma\left(e_{1}+2 e_{2}\right) \\
& \bar{Y}_{1}(m, S, L)=A+S+\theta+R(L)+\left(m \alpha F_{x} W_{x}+C_{g h g} \Delta T_{1} u\right)\left(2 d_{V+} d_{b}\right) \\
& \quad+\Delta V_{1}\left(e_{c o}+s_{c o}+h_{c o}+c_{c o}\right) L_{r} C_{g h g} \\
& \bar{Y}_{2}=C_{s}+\gamma\left[e_{2}\left(C_{p b}+C_{p v}\right)+C_{w}\right]+C_{r}(1-\gamma) e_{1} \\
& \bar{Y}_{3}(m)=\left\{1+(m-2)\left[1-\frac{D}{\bar{X}_{1} P}\right]\right\} \\
& \bar{Y}_{4}(S)=D\left[(1-\alpha) F_{x} w\left(2 d_{V+} d_{b}\right)+C_{g h g}\left(\Delta T_{2} w+\Delta V_{2}\right)\right]+Y B \ln \left(\frac{S_{0}}{S}\right)
\end{aligned}
$$

Substituting the notations, Eq. (13) becomes:

$$
\begin{aligned}
& \operatorname{JTC}(Q, k, L, m, S) \\
& \qquad=\frac{D\left[\bar{Y}_{1}(m, S, L)+m \pi \sigma \sqrt{L} \psi(k)+m Q \bar{Y}_{2}\right]}{m Q \bar{X}_{1}} \\
& +h_{b}\left[\frac{D Q \bar{X}_{2}}{x \bar{X}_{1}}+\frac{Q \bar{X}_{3}}{2}+k \sigma \sqrt{L}\right]+\frac{Q h_{v} \bar{Y}_{3}(m)}{2}+\bar{Y}_{4}(S)
\end{aligned}
$$




\subsection{Solution methodology}

The joint total cost in Eq. (21) is formulated as a function of $(Q, k, L, m, S)$. The following methodology is suggested to find the solutions of the proposed model. Firstly, for a fixed value of $(L, m)$, take the first partial derivative of the joint total cost with respect to $(Q, k, S)$ and setting the result to zero, we have:

$$
\begin{aligned}
& \frac{\partial J T C(Q, k, L, m, S)}{\partial Q}=0 \\
& \frac{-D\left[\bar{Y}_{1}(m, s, L)+m \pi \sigma \sqrt{L} \psi(k)\right]}{m Q^{2} \bar{X}_{1}}+h_{b}\left(\frac{D \bar{X}_{2}}{x \bar{X}_{1}}+\frac{\bar{X}_{3}}{2}\right)+\frac{h_{v} \bar{Y}_{3}(m)}{2}=0 \\
& 2 h_{b}\left(\frac{D \bar{X}_{2}}{x \bar{X}_{1}}+\frac{\bar{X}_{3}}{2}\right)+h_{v} \bar{Y}_{3}(m)=\frac{2 D\left[\bar{Y}_{1}(m, s, L)+m \pi \sigma \sqrt{L} \psi(k)\right]}{m Q^{2} \bar{X}_{1}} \\
& Q^{*}=\sqrt{\frac{2 D\left[\bar{X}_{1}\right.}{\bar{Y}_{1}(m, s, L)}} \frac{2 h_{b}\left(\frac{D \bar{X}_{2}}{x \bar{X}_{1}}+\frac{\bar{X}_{3}}{2}\right)+h_{v} \bar{Y}_{3}(m)}{\partial k \sqrt{L} \psi(k)]} \\
& \frac{\partial J T C(Q, k, L, m, S)}{\partial k}=0
\end{aligned}
$$

$$
\begin{aligned}
& \frac{D m \pi \sigma \sqrt{L}}{m Q \bar{X}_{1}}\left[-1+\Phi\left(k^{*}\right)\right]+h_{b} \sigma \sqrt{L}=0 \\
& {\left[-1+\Phi\left(k^{*}\right)\right]=\frac{-h_{b} m Q \bar{X}_{1} \sigma \sqrt{L}}{D m \pi \sigma \sqrt{L}}} \\
& \Phi\left(k^{*}\right)=1-\frac{h_{b} Q \bar{X}_{1}}{D \pi} \\
& \frac{\partial J T C(Q, k, L, m, S)}{\partial S}=0 \\
& \frac{D}{m Q \bar{X}_{1}}-\frac{Y B}{S}=0 \\
& S^{*}=\frac{m Q Y B \bar{X}_{1}}{D}
\end{aligned}
$$


The following solution procedure is developed to derive the optimal order quantity, safety factor, lead time, setup cost, and the number of shipments in one production cycle.

Step 1 Set $m=1$.

Step 2 For each $L_{i}$ perform the following procedures for $i=0,1,2, \ldots, j$

(2.1) Start with $S_{i 1}=S_{0}$ and $k_{i 1}=0$ [implies $\psi\left(k_{i 1}\right)=0,39894$, which can be obtained by by checking the standard normal table $\varphi\left(k_{i 1}\right)=0,39894$ and $\left.\Phi\left(k_{i 1}\right)=0,5\right]$

(2.2) Substitute $\psi\left(k_{i 1}\right), S_{i 1}$ into $Q_{i 1}=\sqrt{\frac{2 D}{\frac{2 D}{\bar{X}_{1}}\left[\frac{\overline{Y_{1}}(m, s, L)}{m}+\pi \sigma \sqrt{L} \psi(k)\right]}}$ to evaluate $Q_{i 1}$.

(2.3) Check the actual shipping weight, $\left(W_{y}=Q w\right)$; if $\left(W_{y}>W_{x}\right)$ is not satisfied then revise the lot quantity $\left(Q_{i 1}=\frac{W_{x}}{w}\right)$ and go to the next step. Otherwise, $\left(W_{y} \leq W_{x}\right)$, we go on to the next step.

(2.4) Utilize $Q_{i 1}$, and then determine the value of $\Phi\left(k_{i 2}\right)=1-\frac{h_{b} Q_{i} \bar{X}_{1}}{D \pi}$ and $S_{i 2}=\frac{m Q Y B \bar{X}_{1}}{D}$

(2.5) Repeat (2.2) to (2.4) until no change in the value of $\left(Q_{i}, k_{i}, S_{i}\right)$.

(2.6) Compare the decision variables of $S_{i}$ and $S_{0}$.

i). If $S_{i}<S_{0}$, the optimal solution for the given $L_{i}$ is derived. We denote the optimal solution by $\left(Q_{i}{ }^{*}, k_{i}{ }^{*}, S_{i}{ }^{*}\right)$.

ii). If $S_{i} \geq S_{0}$, we set $S_{i}{ }^{*}=S_{0}$ and from Eqs. (23) and (25), determine the new $\left(Q_{i}{ }^{*}, k_{i}{ }^{*}\right)$ using the procedure (2.2) to (2.4). The result is denoted $\left(Q_{i}{ }^{*}, k_{i}{ }^{*}, S_{i}{ }^{*}\right)$.

(2.7) Calculate JTC using Eq. (21).

Step 3 Find $\min _{i=0,1,2, \ldots, j} J T C$ for each model. For optimal $\min _{i=0,1,2, \ldots, j} J T E C$, the decision variables are the optimal for fixed $m$.

Step 4 Set $m=m+1$, repeat steps 2 and 3 to derive JTEC with fixed $m$.

Step 5 If $\operatorname{JTC}\left(Q_{(m)}^{*}, k_{(m)}^{*}, L_{(m)}^{*}, m, S_{(m)}^{*}\right) \leq J T C\left(Q_{(m-1)}^{*}, k_{(m-1)}^{*}, L_{(m-1)}^{*}, m-1, S_{(m-1)}^{*}\right)$, then go to Step 4, otherwise go to Step 6.

Step 6 When the optimal decision variables, $\left(Q^{*}, k^{*}, L^{*}, m^{*}, S^{*}\right)=\left(Q_{(m-1)}^{*}, k_{(m-1)}^{*}, L_{(m-1)}^{*}, m-\right.$ $\left.1, S_{(m-1)}^{*}\right)$, then $\left(Q^{*}, k^{*}, L^{*}, m^{*}, S^{*}\right)$ is the optimal solution

\section{Numerical example and sensitivity analysis}


To illustrate the proposed algorithm, consider an integrated inventory system with the data in Table 2 (adopted from Saga et al. (2019), Wangsa and Wee (2019) and Tiwari et al. (2020)). The lead-time data is shown in Table 3.

Table 2. Input data

\begin{tabular}{|c|c|c|c|}
\hline \multicolumn{2}{|c|}{ Input Values } & \multicolumn{2}{|c|}{ Input Values } \\
\hline $\bar{D}$ & $=10,000$ units/year & $w$ & $=22 \mathrm{lbs} / \mathrm{unit}$ \\
\hline$\sigma$ & $=300$ units $/$ year & $F_{x}$ & $=\$ 0.000040217 / \mathrm{lb} / \mathrm{mile}$ \\
\hline$P$ & $=40,000$ units $/$ year & $W_{x}$ & $=46,000 \mathrm{lbs}$. \\
\hline$x$ & $=65,200$ units $/$ year & $d_{v}$ & $=50$ miles \\
\hline$A$ & $=\$ 30$ & $d_{b}$ & $=600$ miles \\
\hline$S_{0}$ & $=\$ 1400$ & $Y$ & $=0.10 / \$ /$ year \\
\hline$h_{b}$ & $=\$ 8 /$ unit $/$ year & $B$ & $=3,500$ \\
\hline$h_{v}$ & $=\$ 3 /$ unit $/$ year & $\Delta_{v 1}$ & $=0.02264$ ton $-\mathrm{CO}_{2} / \mathrm{kWh}$ \\
\hline$\theta$ & $=\$ 14$ & $\Delta_{v 2}$ & $=0.00965$ ton $-\mathrm{CO}_{2} /$ unit \\
\hline$\pi$ & $=\$ 50 /$ unit & $\Delta_{t 1}$ & $=0.01268$ ton $-\mathrm{CO}_{2} /$ liter \\
\hline$C_{s}$ & $=\$ 0.5 /$ unit & $\Delta_{t 2}$ & $=0.00250$ ton $-\mathrm{CO}_{2} / \mathrm{lb}$ \\
\hline$C_{p b}$ & $=\$ 200 /$ unit & $u$ & $=0.63569$ liters $/ \mathrm{mile}$ \\
\hline$C_{p v}$ & $=\$ 300 /$ unit & $e_{c o}$ & $=154,566 \mathrm{kWh}$ \\
\hline$C_{w}$ & $=\$ 50 /$ unit & $s_{c o}$ & $=115,917 \mathrm{kWh}$ \\
\hline$C_{r}$ & $=\$ 100 /$ unit & $h_{c o}$ & $=38,639 \mathrm{kWh}$ \\
\hline$\beta$ & $=0.04$ & $c_{c o}$ & $=77,278 \mathrm{kWh}$ \\
\hline$\delta$ & $=0.04$ & $L_{r}$ & $=1 \%$ \\
\hline$\rho$ & $=0.04$ & $C_{g h g}$ & $=\$ 20 /$ ton $-\mathrm{CO} 2$ \\
\hline$\alpha$ & $=0.11246$ & & \\
\hline
\end{tabular}

Table 3. Lead time data

\begin{tabular}{cccc}
\hline \hline $\begin{array}{c}\text { Lead time component } \\
(\boldsymbol{i})\end{array}$ & $\begin{array}{c}\text { Normal Duration, } \boldsymbol{d}_{\boldsymbol{i}} \\
(\text { day })\end{array}$ & $\begin{array}{c}\text { Minimum Duration, } \boldsymbol{c}_{\boldsymbol{i}} \\
(\text { day })\end{array}$ & $\begin{array}{c}\text { Unit crashing cost, } \boldsymbol{e}_{\boldsymbol{i}} \\
(\$ / \text { day })\end{array}$ \\
\hline \hline 1 & 20 & 6 & 0.40 \\
2 & 20 & 6 & 1.20 \\
3 & 16 & 9 & 5.00 \\
\hline \hline
\end{tabular}

The probability of defective items and inspection errors follows a uniform distribution, one has:

$$
f(\gamma)=\left\{\begin{array}{l}
\frac{1}{\beta}, 0 \leq \gamma \leq \beta \\
0, \text { otherwise }
\end{array} \quad f\left(e_{1}\right)=\left\{\begin{array}{l}
\frac{1}{\delta}, 0 \leq e_{1} \leq \delta \\
0, \text { otherwise }
\end{array} \quad f\left(e_{2}\right)=\left\{\begin{array}{l}
\frac{1}{\rho}, 0 \leq e_{2} \leq \rho \\
0, \text { otherwise }
\end{array}\right.\right.\right.
$$

and

$$
E[\gamma]=\int_{0}^{\beta} \gamma f(\gamma) d \gamma=\frac{\beta}{2} \quad E\left[e_{1}\right]=\int_{0}^{\delta} e_{1} f\left(e_{1}\right) d e_{1}=\frac{\delta}{2} \quad E\left[e_{2}\right]=\int_{0}^{\rho} e_{2} f\left(e_{2}\right) d e_{2}=\frac{\rho}{2}
$$


Using the above solution procedure, the JTC is $\$ 75,513.64 /$ year, $Q^{*}=1603.53$ units, $k^{*}=$ $1.97, m^{*}=4, W_{y}{ }^{*}=35,277.64$ pounds, lead time $\left(L^{*}\right)=21$ days, defective items based on screening process $\left(B_{1}{ }^{*}\right)=62.86$ units, defective items returned from the market $\left(B_{2}{ }^{*}\right)=0.64$ units, and total emissions $\left(T E^{*}\right)=0.0798$ ton- $\mathrm{CO}_{2}$.

Next, the results of the integrated optimal policy are compared with the independent policy. In the independent model, the players optimize their policy separately to minimize their own total cost. The result shows that the optimal order quantity is $Q^{*}=2070.95$ units, safety factor $k^{*}=1.85, W_{y}{ }^{*}=45,560.94$ lbs., $L^{*}=21$ days, $B_{1}{ }^{*}=81.18$ units, $B_{2}{ }^{*}=0.83$ units, $T E^{*}=$ 0.1115 ton- $\mathrm{CO}_{2}$, and the buyer's total expected cost is $\$ 33,973.26 /$ year. The vendor's total expected cost is $\$ 45,005.78 /$ year. Thus, the total expected cost for the independent policy is $\$ 78,979.04 / y e a r$. The comparison analysis between independent and integrated decisions is shown in Table 4. The integrated decision provides a cost-saving by $\$ 3465.40 /$ year or $4.39 \%$, and emission saving by 0.04 ton- $\mathrm{CO}_{2}$ or $28.44 \%$.

Table 4. The optimal results of the independent and integrated models

\begin{tabular}{|c|c|c|c|}
\hline Parameter & $\begin{array}{l}\text { Buyer's independent } \\
\text { decision }\end{array}$ & Integrated model & Saving \\
\hline$Q$ (units) & $2,070.95$ & $1,603.53$ & \\
\hline$W_{y}(\mathrm{lbs})$ & $45,560.94$ & $35,277.64$ & \\
\hline$L$ (days) & 21 & 21 & \\
\hline$m$ & 1 & 4 & \\
\hline$k$ & 1.85 & 1.97 & \\
\hline$S(\$)$ & 69.61 & 215.60 & \\
\hline$B_{1}$ (units) & 81.18 & 62.86 & \\
\hline$B_{2}$ (units) & 0.83 & 0.64 & \\
\hline$T E\left(\right.$ ton- $\left.\mathrm{CO}_{2}\right)$ & 0.1115 & 0.0798 & $0.04(28.44 \%)$ \\
\hline Buyer's total expected cost (\$) & $33,973.26$ & $31,705.02$ & $2268.25(6.68 \%)$ \\
\hline Vendor's total expected cost $(\$)$ & $45,005.78$ & $43,808.63$ & $1197.16(2.66 \%)$ \\
\hline Joint total cost (\$) & $78,979.04$ & $75,513.64$ & $3465.4(4.39 \%)$ \\
\hline
\end{tabular}

Fig. 1 depicts the impact of type I and type II errors on the JTC. The analysis is examined by changing each of the parameters from $-75 \%$ to $+250 \%$. The result shows that $J T C$ is highly sensitivity to the probability changes in type I error. This is due to a higher probability of rejected items and rework. It is also observed that the type I error has a greater impact on the 
JTC than type II error.

Figs. 2-3 analyzes the effect of these parameters on the defective items after screening $\left(B_{1}\right)$ and after-sales from the market $\left(B_{2}\right)$. Sensitivity analysis is done by varying the parameters from $-75 \%$, to $+250 \%$. Fig. 2 shows that a significantly increase in $B_{1}$ when type I error probabilities increase. The effect of the changes in type II error on $B_{1}$ seems to be insignificant. From Figs. 2-3, it is observed that the values of $B_{1}$ and $B_{2}$ increase as the defective probability increases. Figure 4 shows the impact of type I error, type II error, and defective item on the total emissions. The result shows that if the defective and type I error probabilities increase gradually, the total emissions drastically increase. The total emissions seem to remain unchanged due to the increase in the type II error probability.

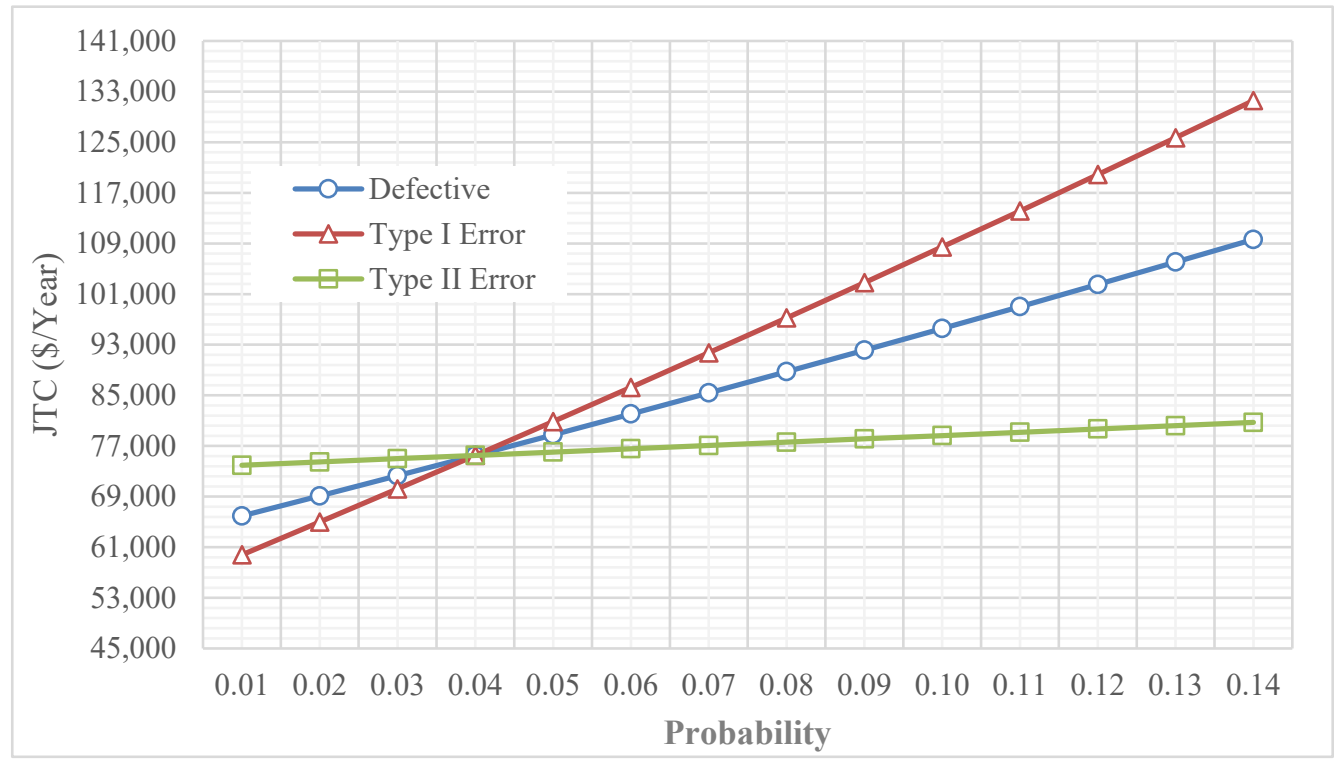

Figure 1. Sensitivity analysis of the probability of defective, type I error, and type II error on the JTEC ( $\$$ year) 


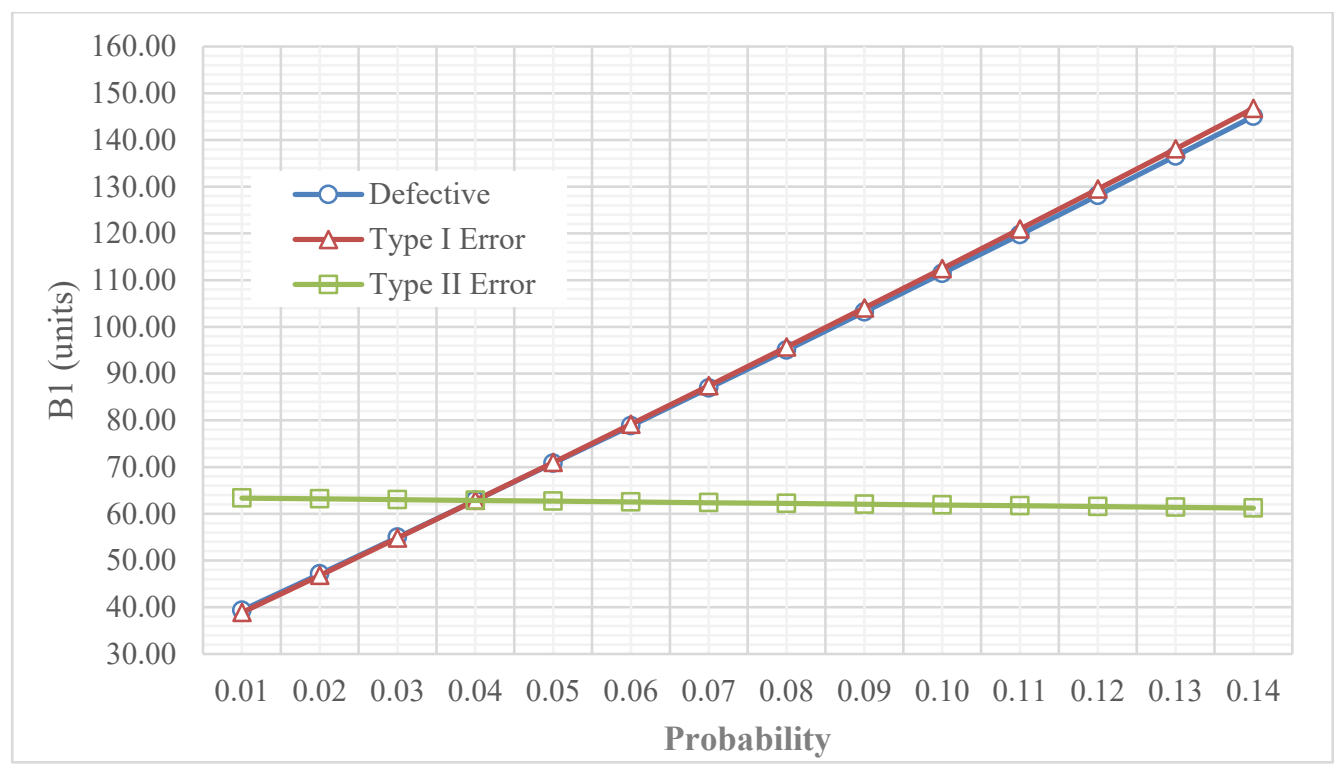

Figure 2. Sensitivity analysis of the probability of defective, type I error, and type II error on the $B_{1}$ (units)

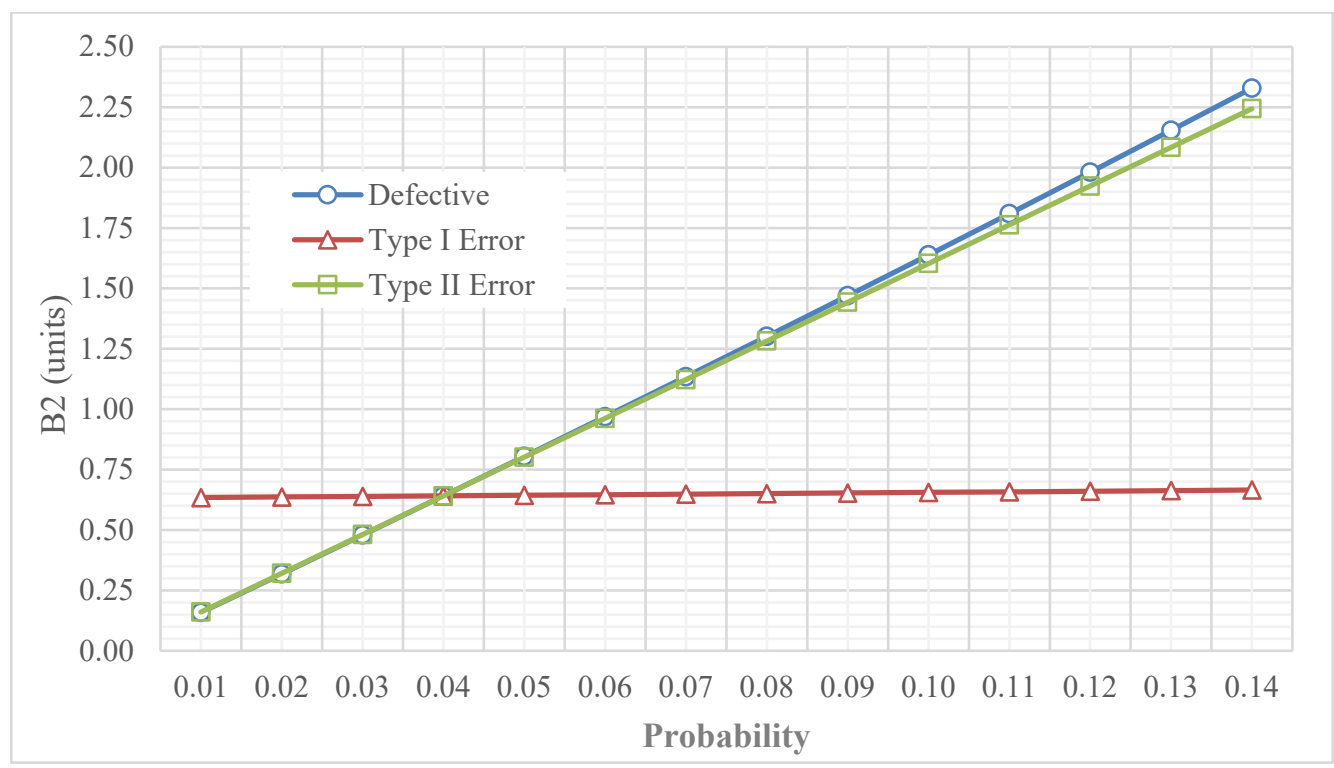

Figure 3. Sensitivity analysis of the probability of defective, type I error, and type II error on the $B_{2}$ (units) 


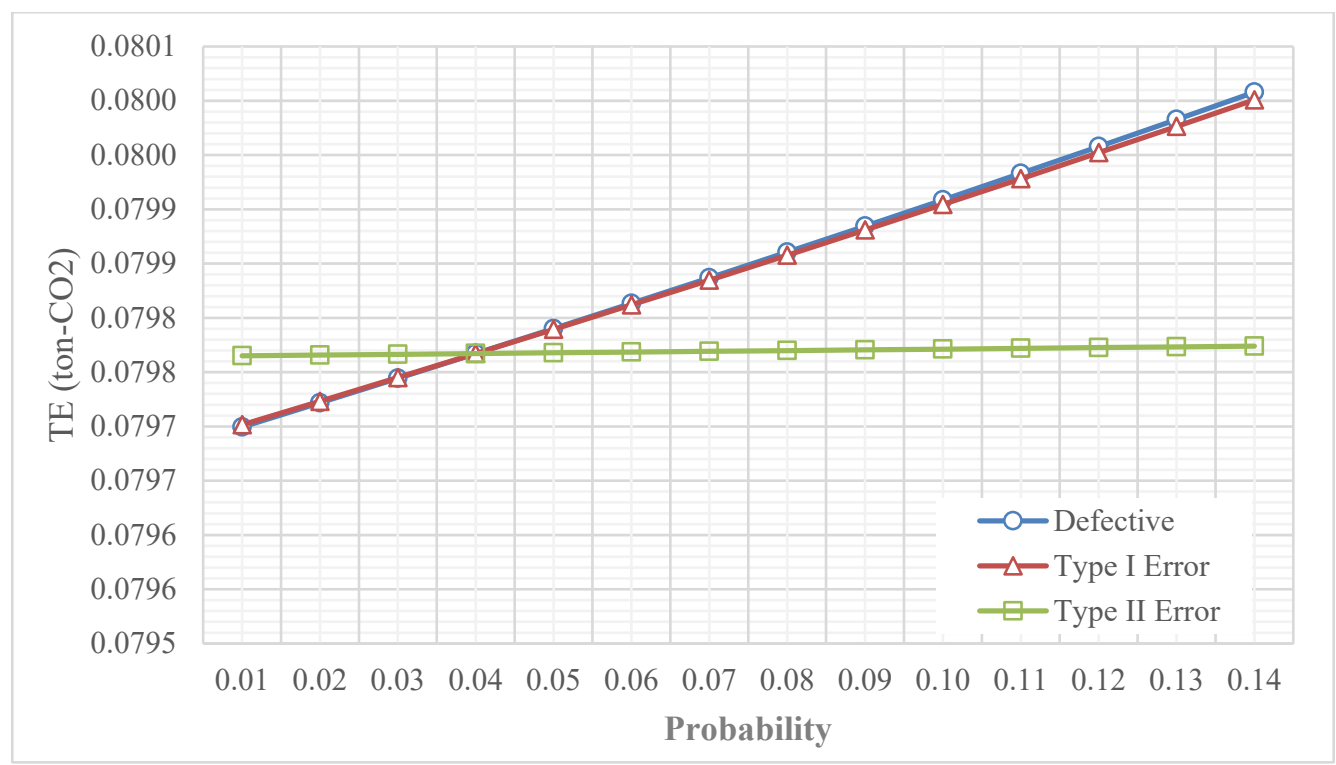

Figure 4. Sensitivity analysis of the probability of defective, type I error, and type II error on the $T E\left(\right.$ ton- $\left.\mathrm{CO}_{2}\right)$

Table 4 and Fig. 5 show that the total expected cost, lot size, safety factor, the number of deliveries, lead time, and setup cost are sensitive to changes in parameters: $D, P, \beta, \delta, \rho, h_{b}$, $h_{v}, x, S_{0}, Y$, and $C_{g h g}$. In the sensitivity analysis, the parameter values vary from $-50 \%$ to $+50 \%$ and the comparison between independent and integrated decisions is also provided. Fig. 4 shows that the JTC saving increases respectively by $2.89 \%, 1.3 \%$ and $5.24 \%$ when the buyer's holding cost $\left(h_{b}\right)$, demand $(D)$ and carbon emission cost $\left(C_{g h g}\right)$ increase. The cost savings are insignificant for the increase in defective rate probability, type II error probability, screening rate, initial setup cost, and setup cost reduction investment. 


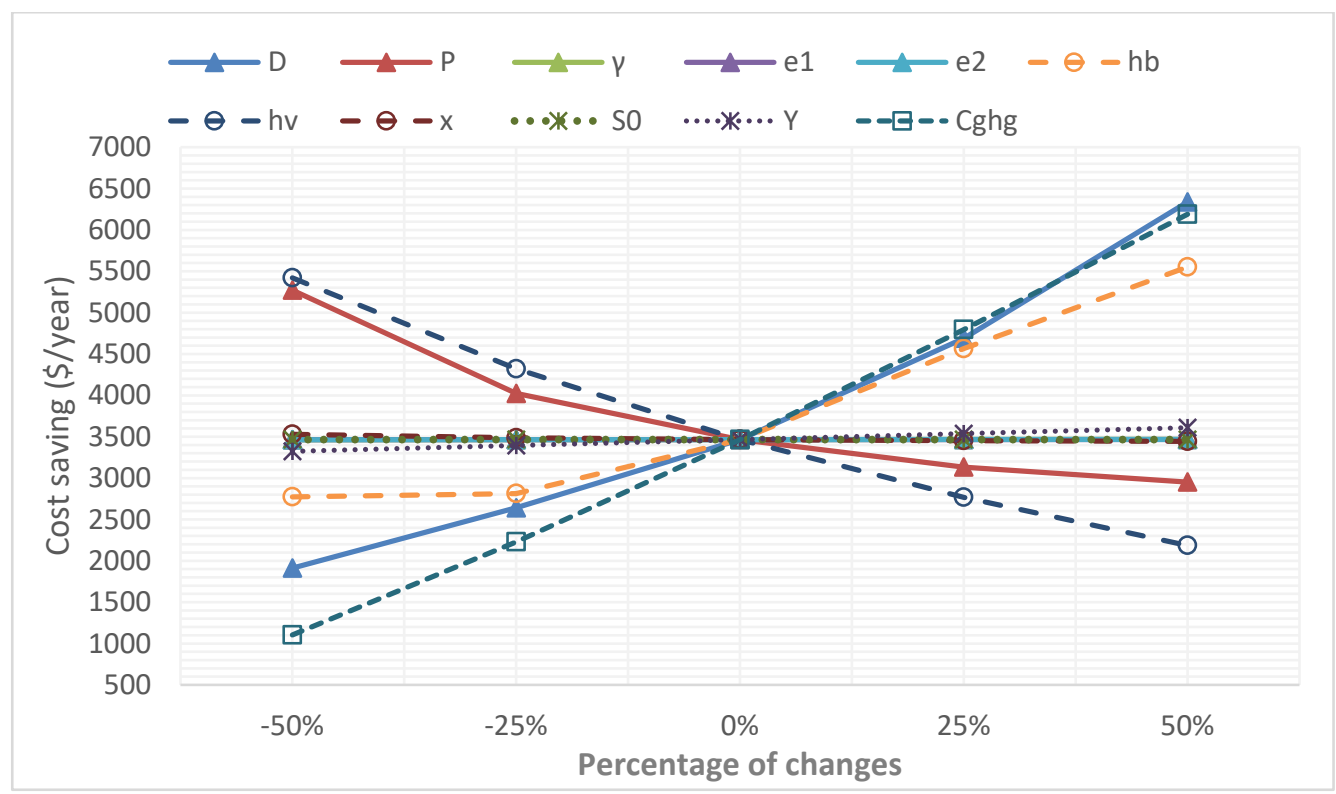

Figure 5. Sensitivity analysis $D, P, \beta, \delta, \rho, h_{b}, h_{v}, x, S_{0}, Y$, and $C_{g h g}$, on cost-saving with compared the independent optimal policy to the integrated optimal policy. 
Table 4. The sensitivity analysis

\begin{tabular}{|c|c|c|c|c|c|c|c|c|c|c|c|c|c|c|c|c|c|}
\hline \multirow{2}{*}{ Parameter } & \multirow{2}{*}{ Values } & \multicolumn{6}{|c|}{ Buyer's independent decision } & \multicolumn{8}{|c|}{ Integrated model } & \multicolumn{2}{|c|}{ Cost Saving } \\
\hline & & $Q^{* *}$ & $\boldsymbol{k}^{*}$ & $L^{\prime *}$ & $S^{*}$ & $T E C_{b}()$. & $T E C_{v}()$. & $Q^{*}$ & $k^{*}$ & $L^{* *}$ & $m^{\prime *}$ & $S^{*}$ & $T E C_{b}()$. & $T E C_{v}()$. & 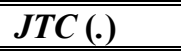 & \$/year & $\%$ \\
\hline \multirow{5}{*}{$\begin{array}{l}\text { Demand of } \\
\text { the buyer } \\
\text { (D) }\end{array}$} & 25,000 & $1,491.00$ & 1.69 & 21 & 100.24 & $19,754.55$ & $24,673.10$ & $1,281.27$ & 1.76 & 21 & 3 & 258.41 & $18,611.20$ & $23,904.77$ & $42,515.97$ & $1,1,911.68$ & 4.30 \\
\hline & 7,500 & $1,806.20$ & 1.79 & 21 & 80.95 & $26,990.58$ & $34,941.18$ & $1,567.95$ & 1.85 & 21 & 3 & 210.82 & $25,629.54$ & $33,661.98$ & $59,291.52$ & $2,640.24$ & 4.26 \\
\hline & 10,000 & $2,070.95$ & 1.85 & 21 & 69.61 & $33,973.26$ & $45,005.78$ & $1,603.53$ & 1.97 & 21 & 4 & 215.60 & $31,705.02$ & $43,808.63$ & $75,513.64$ & $3,465.39$ & 4.39 \\
\hline & & $2,090.91$ & 1.95 & 21 & 56.23 & $40,199.10$ & $55,886.64$ & $1,810.06$ & 2.01 & 21 & 4 & 194.70 & $38,331.55$ & $53,064.00$ & $91,395.55$ & $4,690.20$ & 4.88 \\
\hline & 15,000 & $2,090.91$ & 2.03 & 28 & 46.86 & $46,351.20$ & $66,832.75$ & $2,090.91$ & 2.03 & 21 & 3 & 140.57 & $45,287.95$ & $61,558.93$ & $106,846.87$ & $6,337.08$ & 5.60 \\
\hline \multirow{5}{*}{$\begin{array}{l}\text { Production } \\
\text { rate }(P)\end{array}$} & 20,000 & 070.95 & .85 & 21 & 699.61 & $33,973.26$ & $245,814.41$ & $101,566.46$ & 1.98 & 21 & $\overline{5}$ & 263.28 & $31,526.18$ & 42,989.70 & $74,515.87$ & $\begin{array}{l}5,271.79 \\
\end{array}$ & 6.61 \\
\hline &, 000 & $2,070.95$ & 1.85 & 21 & 69.61 & $33,973.26$ & $45,275.32$ & $1,632.44$ & 1.96 & 21 & 4 & 219.49 & $31,790.03$ & $43,434.66$ & $75,224.69$ & $4,023.89$ & 5.08 \\
\hline & 40,000 & $2,070.95$ & 1.85 & 21 & 69.61 & $33,973.26$ & 45,005 & $1,603.53$ & 1.97 & 21 & 4 & 215.60 & $31,705.02$ & $43,808.63$ & 3.64 & .39 & 4.39 \\
\hline & 50,000 & $2,070.95$ & 1.85 & 21 & 69.61 & 33,9 & 44,84 & $1,586.90$ & 1.97 & 21 & 4 & & 6.52 & $44,028.04$ & & & 3.97 \\
\hline & 60,000 & $2,070.95$ & 1.85 & 21 & 69.61 & $33,973.26$ & $44,736.24$ & $1,796.27$ & 1.92 & 21 & 3 & 181.14 & 32,3 & $43,367.57$ & 3.00 & .50 & 3.75 \\
\hline \multirow{5}{*}{$\begin{array}{l}\text { Defective } \\
\text { rate } \\
\text { probability } \\
(\gamma)\end{array}$} & 0.02 & $2,054.03$ & 1.85 & 21 & 69.75 & $33,481.27$ & $39,083.47$ & $1,1,592.11$ & 1.96 & 21 & 4 & 216.25 & $31,222.30$ & $37,879.34$ & $699,101.64$ & $3,463.10$ & 4.77 \\
\hline & 0.03 & 62.46 & 1.85 & 21 & 69.68 & .98 & & $1,597.80$ & 1.97 & 21 & 4 & .93 & .38 & 8.99 & .37 & 15 & 4.57 \\
\hline & 0.04 & $2,070.95$ & 1.85 & 21 & 69.61 & $33,973.26$ & $45,005.78$ & $1,603.53$ & 1.97 & 21 & 4 & 215.60 & $31,705.02$ & $43,808.63$ & $75,513.64$ & $3,465.39$ & 4.39 \\
\hline & 0.05 & $2,079.49$ & 1.86 & 21 & 69.54 & $34,223.15$ & $48,012.63$ & $1,609.30$ & 1.97 & 21 & 4 & 215.28 & $31,950.24$ & $46,818.72$ & 68.95 & $3,466.82$ & 4.22 \\
\hline & 0.06 & $2,088.09$ & 1.86 & 21 & 69.47 & $34,475.69$ & $51,050.57$ & $1,615.12$ & 1.97 & 21 & 4 & 214.95 & $32,198.08$ & $49,859.73$ & $82,057.81$ & $3,468.45$ & 4.06 \\
\hline \multirow{5}{*}{$\begin{array}{l}\text { Type I } \\
\text { inspection } \\
\text { error } \\
\text { probability } \\
\left(e_{1}\right) \\
\end{array}$} & 0.02 & $\overline{553.67}$ & 1.85 & 21 & "69.74 & $333,895.26$ & 34,5 & $1,1,591.96$ & 1.96 & 21 & 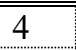 & 216.23 & 6.31 & 3.94 & 0.25 & $\overline{1.81}$ & $\bar{~} 5.06$ \\
\hline & 0.03 & $2,062.28$ & 1.85 & 21 & 69.68 & $33,934.02$ & 39 , & $1,597.72$ & 1.97 & 21 & 4 & 215.92 & 0.44 & 9.78 & 0.21 & 5.01 & 4.70 \\
\hline & 0.04 & $2,070.95$ & 1.85 & 21 & 69.61 & $33,973.26$ & 45, & $1,603.53$ & 1.97 & 21 & 4 & 215.60 & 5.02 & 8.63 & 3.64 & .39 & 4.39 \\
\hline & 0.05 & $2,079.68$ & 1.86 & 21 & 69.55 & $34,012.98$ & $50,314.34$ & $1,609.38$ & 1.97 & 21 & 4 & 215.29 & $31,740.05$ & $49,121.30$ & $80,861.36$ & $3,465.96$ & 4.11 \\
\hline & 0.06 & $2,088.46$ & 1.86 & 21 & 69.49 & $34,053.18$ & $55,677.73$ & $1,615.27$ & 1.97 & 21 & 4 & 214.97 & $31,775.56$ & $54,488.64$ & $86,264.19$ & $3,466.71$ & 3.86 \\
\hline \multirow{5}{*}{$\begin{array}{l}\text { Type II } \\
\text { inspection } \\
\text { error } \\
\text { probability } \\
\left(e_{2}\right)\end{array}$} & 0.02 & 2, & 1.85 & 21 & 68 & 5 & 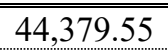 & 7 & 1 & 21 & 4 & 62 & 9 & 14 & 3 & 57 & 4.44 \\
\hline & 0.03 & $2,071.14$ & 1.85 & 21 & 69.62 & $33,764.16$ & $44,692.66$ & $1,603.60$ & 1.97 & 21 & 4 & 215.61 & $31,495.90$ & $43,496.38$ & $74,992.29$ & .53 & 4.42 \\
\hline & 0.04 & $2,070.95$ & 1.85 & 21 & 69.61 & $33,973.26$ & $45,005.78$ & $1,603.53$ & 1.97 & 21 & 4 & 215.60 & $31,705.02$ & $43,808.63$ & $75,513.64$ & $3,465.39$ & 4.39 \\
\hline & 0.05 & $2,070.77$ & 1.85 & 21 & 69.61 & $34,182.36$ & $45,318.89$ & $1,603.46$ & 1.97 & 21 & 4 & 215.59 & & $44,120.87$ & 5.00 & $3,466.26$ & 4.36 \\
\hline & 0.06 & $2,070.58$ & 1.85 & 21 & 69.60 & $34,391.47$ & $45,632.01$ & $1,603.38$ & 1.97 & 21 & 4 & 215.58 & $32,123.24$ & $44,433.12$ & $76,556.36$ & $3,467.12$ & 4.33 \\
\hline \multirow{5}{*}{$\begin{array}{l}\text { Buyer's } \\
\text { holding } \\
\text { cost }\left(h_{b}\right)\end{array}$} & 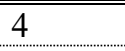 & 91 & 2.14 & 28 & 770.28 & $29,229.93$ & "44,926.25 & $2,2,090.91$ & 2.14 & 21 & 2 & 0.57 & $28,736.24$ & $\overline{7.21}$ & .45 & $2,772.73$ & 3.74 \\
\hline & 6 & $2,090.91$ & 1.98 & 21 & 70.28 & $31,662.92$ & $44,926.25$ & $2,090.91$ & 1.98 & 21 & 2 & 140.57 & $31,129.46$ & $42,647.21$ & $73,776.67$ & $2,812.50$ & 3.67 \\
\hline & 8 & $2,070.95$ & 1.85 & 21 & 69.61 & $33,973.26$ & $45,005.78$ & $1,603.53$ & 1.97 & 21 & 4 & 215.60 & $31,705.02$ & $43,808.63$ & $75,513.64$ & $3,465.39$ & 4.39 \\
\hline & 10 & $1,859.92$ & 1.80 & 21 & 62.52 & $35,518.48$ & $45,959.11$ & $1,511.97$ & 1.90 & 21 & 4 & 203.29 & $33,251.98$ & $43,660.69$ & $76,912.67$ & $4,564.91$ & 5.60 \\
\hline & 12 & $1,704.25$ & 1.76 & 21 & 57.29 & $36,947.00$ & $46,823.58$ & $1,319.16$ & 1.87 & 21 & 5 & 221.71 & $34,091.74$ & $44,126.67$ & $78,218.41$ & $5,552.17$ & 6.63 \\
\hline
\end{tabular}




\begin{tabular}{|c|c|c|c|c|c|c|c|c|c|c|c|c|c|c|c|c|c|}
\hline \multirow{2}{*}{ Parameter } & \multirow{2}{*}{ Values } & \multicolumn{6}{|c|}{ Buyer's independent decision } & \multicolumn{8}{|c|}{ Integrated model } & \multicolumn{2}{|c|}{ Cost Saving } \\
\hline & & $Q^{*}$ & $\boldsymbol{k}^{*}$ & $L^{*}$ & $S^{*}$ & $T E C_{b}()$. & $T E C_{v}()$. & $Q^{*}$ & $\boldsymbol{k}^{*}$ & $L^{*}$ & $m *$ & $S^{*}$ & $T E C_{b}()$. & $T E C_{v}()$. & $J T C()$. & \$/year & $\%$ \\
\hline \multirow{5}{*}{$\begin{array}{l}\text { Vendor's } \\
\text { holding } \\
\text { cost }\left(h_{v}\right)\end{array}$} & 1.50 & $2,070.95$ & 1.85 & 21 & 69.61 & $33,973.26$ & $44,601.46$ & $1,718.38$ & 1.94 & 21 & 5 & 288.81 & $31,982.74$ & $441,171.45$ & $73,154.19$ & $5,420.53$ & 6.90 \\
\hline & 2.25 & $2,070.95$ & 1.85 & 21 & 69.61 & $33,973.26$ & $44,803.62$ & $1,714.57$ & 1.94 & 21 & 4 & 230.53 & $32,036.09$ & $42,420.07$ & $74,456.16$ & $4,320.72$ & 5.48 \\
\hline & 3 & $2,070.95$ & 1.85 & 21 & 69.61 & $33,973.26$ & $45,005.78$ & $1,603.53$ & 1.97 & 21 & 4 & 215.60 & $31,705.02$ & $43,808.63$ & $75,513.64$ & $3,465.39$ & 4.39 \\
\hline & 3.75 & $2,070.95$ & 1.85 & 21 & 69.61 & $33,973.26$ & $45,207.94$ & $1,727.69$ & 1.93 & 21 & 3 & 174.22 & $32,183.59$ & $44,229.75$ & $76,413.34$ & $2,767.86$ & 3.50 \\
\hline & 4.5 & $2,070.95$ & 1.85 & 21 & 69.61 & $33,973.26$ & $45,410.09$ & $1,652.05$ & 1.95 & 21 & 3 & 166.60 & $31,960.69$ & $45,237.38$ & $77,198.07$ & $2,185.28$ & 2.75 \\
\hline \multirow{5}{*}{$\begin{array}{l}\text { Screening } \\
\text { rate }(x)\end{array}$} & 3260 & $2,057.31$ & 1.86 & 21 & 69.15 & $34,036.96$ & 4 45,061.08 & $1,598.14$ & 1.97 & 21 & 4 & 214.88 & $31,769.30$ & 43,799.34 & $775,568.64$ & $3,529.40$ & 4.46 \\
\hline & 48900 & $2,066.38$ & 1.86 & 21 & 69.46 & $33,994.54$ & $45,024.25$ & $1,601.73$ & 1.97 & 21 & 4 & 215.36 & $31,726.48$ & $43,805.51$ & $75,532.00$ & $3,486.79$ & 4.41 \\
\hline & 65,200 & $2,070.95$ & 1.85 & 21 & 69.61 & $33,973.26$ & $45,005.78$ & $1,603.53$ & 1.97 & 21 & 4 & 215.60 & $31,705.02$ & $43,808.63$ & $75,513.64$ & $3,465.39$ & 4.39 \\
\hline & 81500 & $2,073.71$ & 1.85 & 21 & 69.71 & $33,960.47$ & $44,994.68$ & $1,604.61$ & 1.97 & 21 & 4 & 215.75 & $31,692.12$ & $43,810.50$ & $75,502.62$ & 2.53 & 4.37 \\
\hline & 97800 & $2,075.56$ & 1.85 & 21 & 69.77 & $33,951.93$ & $44,987.28$ & $1,605.34$ & 1.97 & 21 & 4 & 215.85 & $31,683.51$ & $43,811.76$ & $75,495.27$ & $3,443.94$ & 4.36 \\
\hline \multirow{5}{*}{$\begin{array}{l}\text { Initial } \\
\text { setup cost } \\
(Y)\end{array}$} & 7700 & $2,070.95$ & 1.85 & 21 & "69.61 & $33,973.26$ & "44,763.18 & $1,603.53$ & 1.97 & 21 & $\overline{74}$ & 215.60 & $31,705.02$ & "43,566.03 & $7 \overline{c 75,271.04}$ & $3,465.39$ & 4.40 \\
\hline & 1050 & $2,070.95$ & 1.85 & 21 & 69.61 & $33,973.26$ & $44,905.09$ & $1,603.53$ & 1.97 & 21 & 4 & 215.60 & $31,705.02$ & $43,707.94$ & $75,412.95$ & $3,465.39$ & 4.39 \\
\hline & 1,400 & $2,070.95$ & 1.85 & 21 & 69.61 & $33,973.26$ & $45,005.78$ & $1,603.53$ & 1.97 & 21 & 4 & 215.60 & $31,705.02$ & $43,808.63$ & $75,513.64$ & $3,465.39$ & 4.39 \\
\hline & 1750 & $2,070.95$ & 1.85 & 21 & 69.61 & $33,973.26$ & $45,083.88$ & $1,603.53$ & 1.97 & 21 & 4 & 215.60 & $31,705.02$ & $43,886.73$ & $75,591.74$ & $3,465.39$ & 4.38 \\
\hline & 2100 & $2,070.95$ & 1.85 & 21 & 69.61 & $33,973.26$ & $45,147.69$ & $1,603.53$ & 1.97 & 21 & 4 & 215.60 & $31,705.02$ & $43,950.54$ & $75,655.56$ & $3,465.39$ & 4.38 \\
\hline \multirow{5}{*}{$\begin{array}{l}\text { Vendor } \\
\text { capital } \\
\text { investment } \\
(Y)\end{array}$} & 0.05 & $2,070.95$ & 1.85 & 21 & 34.81 & $33,973.26$ & $44,426.86$ & $1,591.77$ & 1.97 & 21 & 4 & 107.01 & $31,670.69$ & $43,406.07$ & $75,076.76$ & $3,323.35$ & 4.24 \\
\hline & 0.075 & $2,070.95$ & 1.85 & 21 & 52.21 & $33,973.26$ & $44,731.18$ & $1,597.64$ & 1.97 & 21 & 4 & 161.11 & $31,687.80$ & $43,622.48$ & 0.28 & $3,394.16$ & 4.31 \\
\hline & 0.10 & $2,070.95$ & 1.85 & 21 & 69.61 & & & $1,603.53$ & 1.97 & 21 & 4 & 215.60 & $31,705.02$ & $43,808.63$ & & $3,465.39$ & 4.39 \\
\hline & 0.125 & $2,070.95$ & 1.85 & 21 & 87.02 & $33,973.26$ & $45,258.26$ & $1,609.44$ & 1.96 & 21 & 4 & 270.50 & $31,722.33$ & $43,972.14$ & $75,694.47$ & $3,537.05$ & 4.46 \\
\hline & 0.15 & $2,070.95$ & 1.85 & 21 & 104.42 & $33,973.26$ & $45,493.13$ & $1,615.38$ & 1.96 & 21 & 4 & 325.80 & $31,739.74$ & $44,117.51$ & $75,857.25$ & $3,609.14$ & 4.54 \\
\hline \multirow{5}{*}{$\begin{array}{l}\text { Carbon } \\
\text { emission } \\
\text { cost } \\
\left(C_{g h g}\right)\end{array}$} & 10 & $2,033.73$ & 18.86 & 21 & 268.36 & $28,077.44$ & 3 & $1,1,667.75$ & 1.95 & 21 & 3 & 168.18 & $26,389.06$ & "40,299.33 & "66,688.38 & $101,103.78$ & 1.63 \\
\hline & 15 & $2,052.42$ & 1.86 & 21 & 68.99 & $31,026.75$ & $42,379.56$ & $1,742.80$ & 1.93 & 21 & 3 & 175.75 & $29,422.61$ & $41,754.95$ & $71,177.56$ & $2,228.75$ & 3.04 \\
\hline & 20 & $2,070.95$ & 1.85 & 21 & 69.61 & $33,973.26$ & $45,005.78$ & $1,603.53$ & 1.97 & 21 & 4 & 215.60 & $31,705.02$ & $43,808.63$ & $75,513.64$ & $3,465.39$ & 4.39 \\
\hline & 25 & $2,089.31$ & 1.85 & 21 & 70.23 & $36,917.07$ & $47,594.90$ & $1,653.71$ & 1.95 & 21 & 4 & 222.35 & $34,647.53$ & $45,069.30$ & $79,716.82$ & $4,795.15$ & 5.67 \\
\hline & 30 & $2,090.91$ & 1.85 & 21 & 70.28 & $39,812.09$ & $50,247.64$ & $1,531.01$ & 1.99 & 21 & 5 & 257.32 & $36,999.83$ & $46,870.22$ & $83,870.05$ & $6,189.68$ & 6.87 \\
\hline
\end{tabular}




\section{Conclusions and future research directions}

In this study, type I and II errors are considered for a single vendor-single buyer system with defective items, setup cost reduction and controllable lead time. The freight cost and emission cost are also incorporated. The freight cost is derived as a function of the weight of shipping and the vendor's distance to the buyer. The emission cost is formulated as a function of direct and indirect emissions generated from vendor and buyer activities. The objective of the study is to minimize the joint total cost incurred by the integrated inventory system. The results obtained from the numerical example show that the defective rate and inspection errors have a pronounced impact on costs, lead time, and the total carbon emissions. The changes in type I error and type II error give a significant impact on the shipment lot which leads to the changes in the total cost and the total emissions. Our study provides managerial insights for management in controlling the system to maintain an appropriate level of total cost and carbon emissions. The results also show that the integrated policy performs better than the independent policy. Future research can be done to consider the impact of returned products, as well as defective raw materials.

\section{Declaration of competing interest}

The authors declare that they have no known competing financial interests or personal relationships that could have appeared to influence the work reported in this paper.

\section{References}

Eroglu, A., \& Ozdemir, G. (2007). An economic order quantity model with defective items and shortages. International Journal of Production Economics, 106(2), 544-549.

Goyal, S. K., \& Cárdenas-Barrón, L. E. (2002). Note on: economic production quantity model for items with imperfect quality-a practical approach. International Journal of Production Economics, 77(1), 85-87.

Goyal, S. K., Huang, C. K., \& Chen, K. C. (2003). A simple integrated production policy of an imperfect item for vendor and buyer. Production Planning \& Control, 14(7), 596-602.

Hsu, J.T., \& Hsu, L.F. (2012) An integrated single-vendor single-buyer production-inventory model for items with imperfect quality and inspection errors. International Journal of 
Industrial Engineering Computations, 3, 703-720.

Jauhari, W. A. (2016). Integrated vendor-buyer model with defective items, inspection error and stochastic demand. International Journal of Mathematics in Operational Research, $8(3), 342-359$.

Jauhari, W. A. (2018). A collaborative inventory model for vendor-buyer system with stochastic demand, defective items and carbon emission cost. International Journal of Logistics Systems and Management, 29(2), 241-269.

Jauhari, W. A., Widianto, I. P., \& Rosyidi, C. N. (2017). A supply chain inventory model for vendor-buyer system with defective items and imperfect inspection process. International Journal of Mathematics in Operational Research, 11(4), 450-469.

Khan, M., Hussain, M., \& Saber, H. (2017). A vendor-buyer supply chain model with stochastic lead times and screening errors. International Journal of Operational Research, DOI: 10.1504/IJOR.2017.10003467.

Khan, M., Jaber, M. Y., \& Bonney, M. (2011). An economic order quantity (EOQ) for items with imperfect quality and inspection errors. International Journal of Production Economics, 133(1), 113-118.

Konstantaras, I., Goyal, S. K., \& Papachristos, S. (2007). Economic ordering policy for an item with imperfect quality subject to the in-house inspection. International Journal of Systems Science, 38(6), 473-482.

Maddah, B., \& Jaber, M. Y. (2008). Economic order quantity for items with imperfect quality: revisited. International Journal of Production Economics, 112(2), 808-815.

Papachristos, S., \& Konstantaras, I. (2006). Economic ordering quantity models for items with imperfect quality. International Journal of Production Economics, 100(1), 148-154.

Saga, R. S., Jauhari, W. A., Laksono, P. W., \& Dwicahyani, A. R. (2019). Investigating carbon emissions in a production-inventory model under imperfect production, inspection errors and service-level constraint. International Journal of Logistics Systems and Management, 34(1), 29-55.

Salameh, M. K., \& Jaber, M. Y. (2000). Economic production quantity model for items with imperfect quality. International Journal of Production Economics, 64(1), 59-64.

Tiwari, S., Daryanto, Y., \& Wee, H. M. (2018a). Sustainable inventory management with deteriorating and imperfect quality items considering carbon emission. Journal of Cleaner Production, 192, 281-292.

Tiwari, S., Kazemi, N., Modak, N. M., Cárdenas-Barrón, L. E., \& Sarkar, S. (2020). The effect of human errors on an integrated stochastic supply chain model with setup cost reduction and backorder price discount. International Journal of Production Economics, 107643.

Tiwari, S., Sana, S. S., \& Sarkar, S. (2018b). Joint economic lot sizing model with stochastic demand and controllable lead-time by reducing ordering cost and setup cost. Revista de la Real Academia de Ciencias Exactas, Físicas y Naturales. Serie A. Matemáticas, 112(4), 1075-1099.

Wang, C. H. (2005). Integrated production and product inspection policy for a deteriorating production system. International Journal of Production Economics, 95(1), 123-134.

Wangsa, I. (2017). Greenhouse gas penalty and incentive policies for a joint economic lot size model with industrial and transport emissions. International Journal of Industrial Engineering Computations, 8(4), 453-480.

Wangsa, I. D., \& Wee, H. M. (2019). A vendor-buyer inventory model for defective items with errors in inspection, stochastic lead time and freight cost. INFOR: Information Systems and Operational Research, 57(4), 597-622. 
Wee, H. M., Yu, J., \& Chen, M. C. (2007). Optimal inventory model for items with imperfect quality and shortage backordering. Omega, 35(1), 7-11. 
Figures

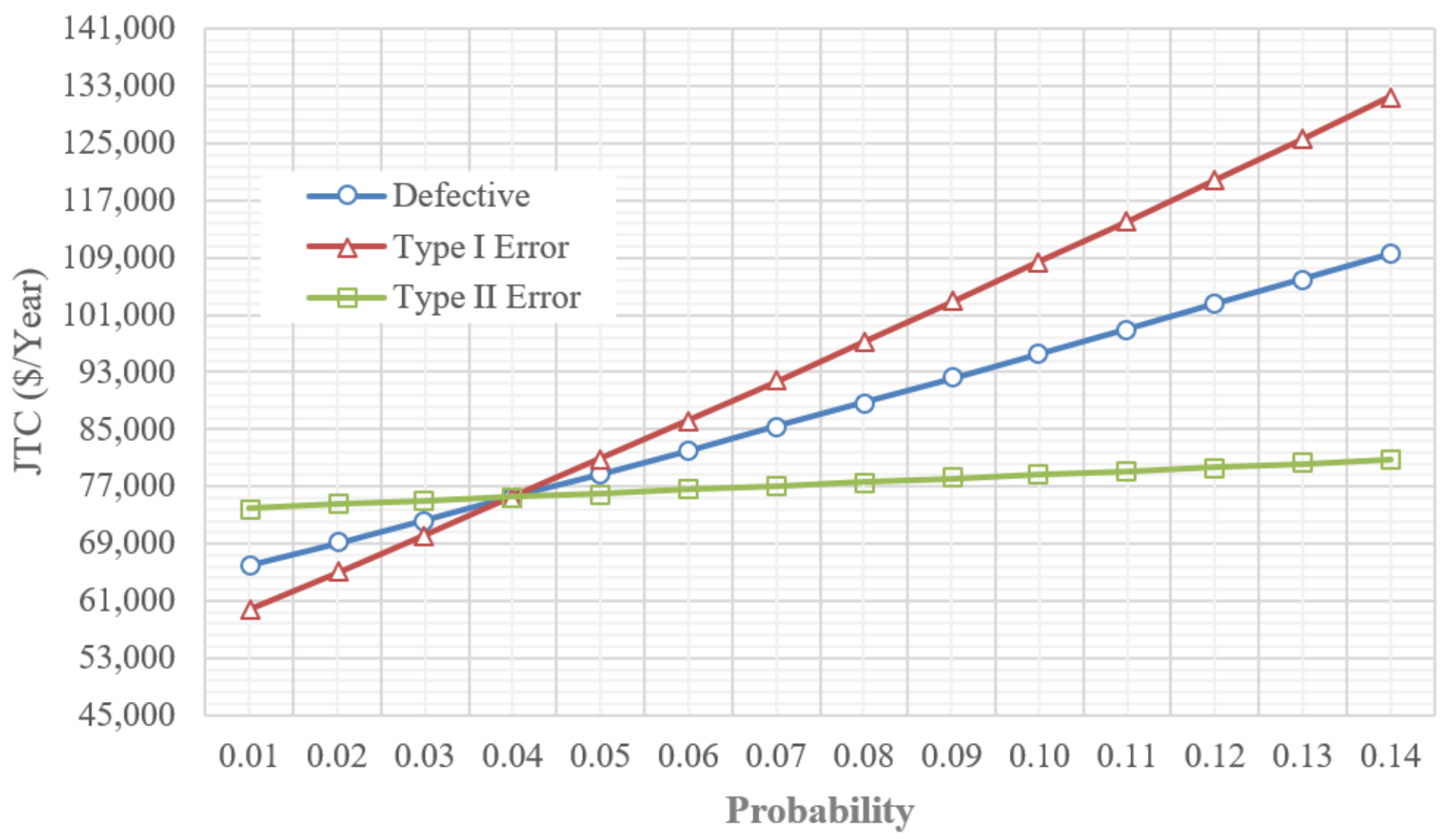

\section{Figure 1}

Sensitivity analysis of the probability of defective, type I error, and type II error on the JTEC (\$/year) 


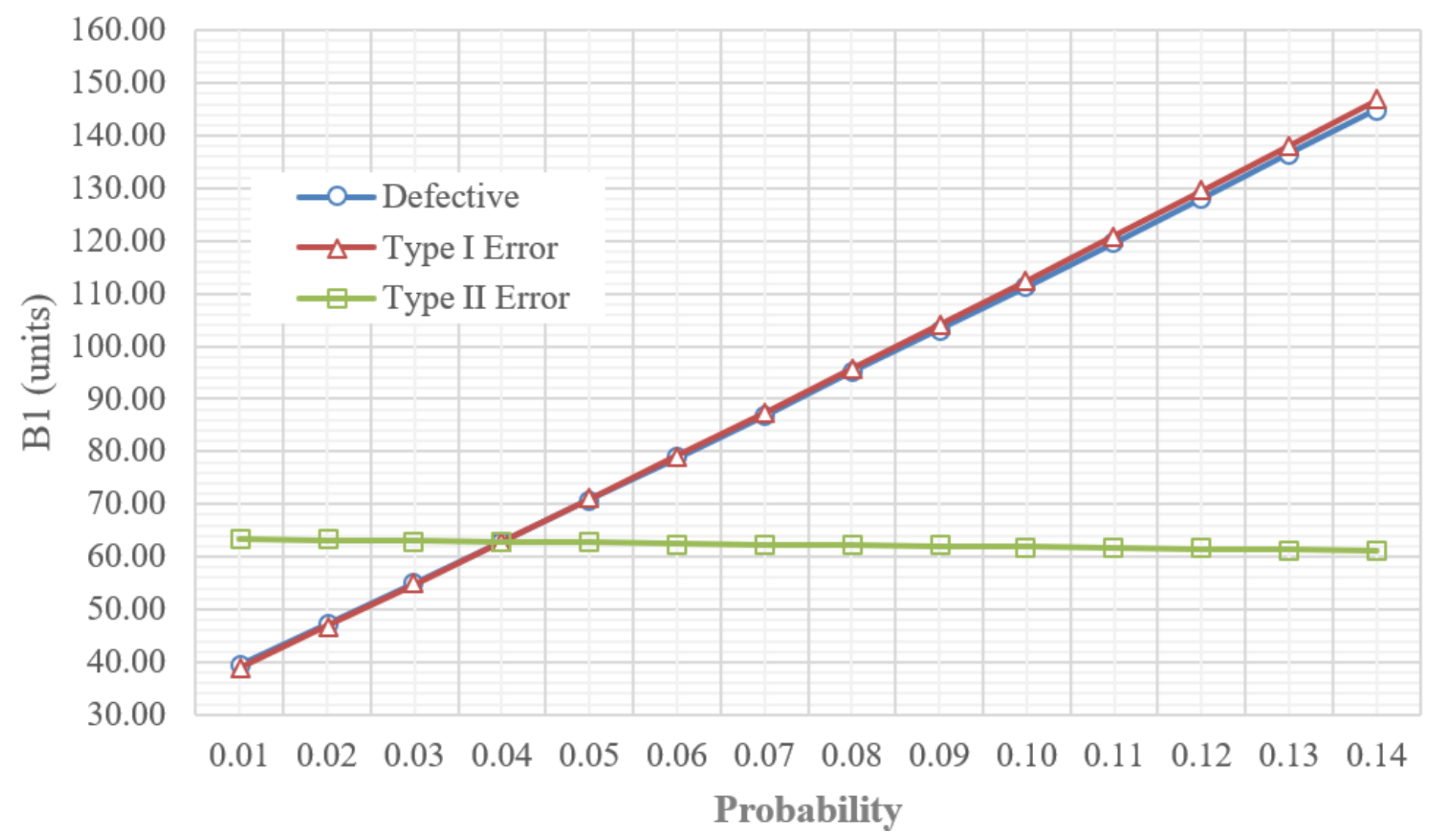

Figure 2

Sensitivity analysis of the probability of defective, type I error, and type II error on the B_1 (units)

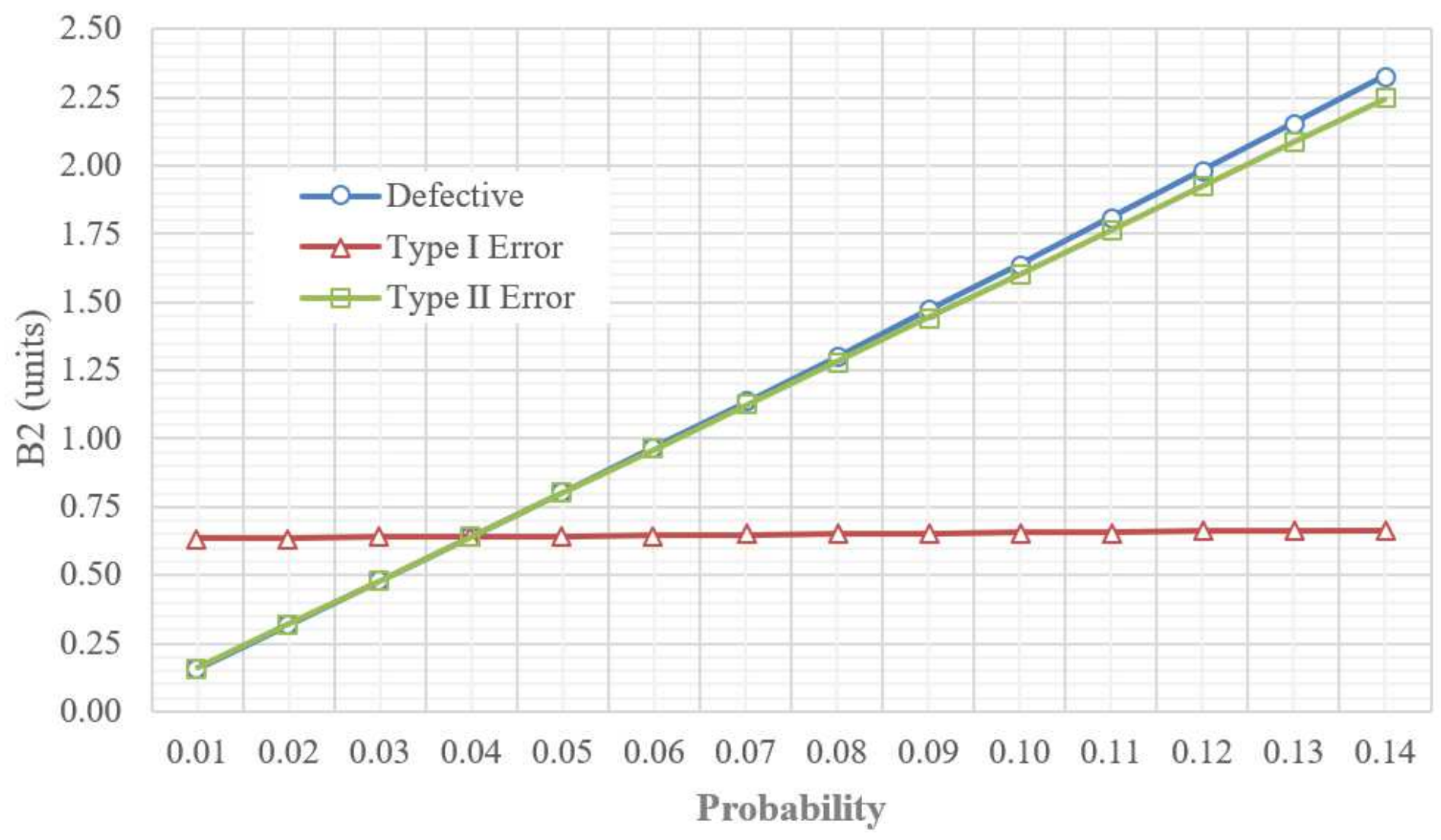


Figure 3

Sensitivity analysis of the probability of defective, type I error, and type II error on the B_2 (units)

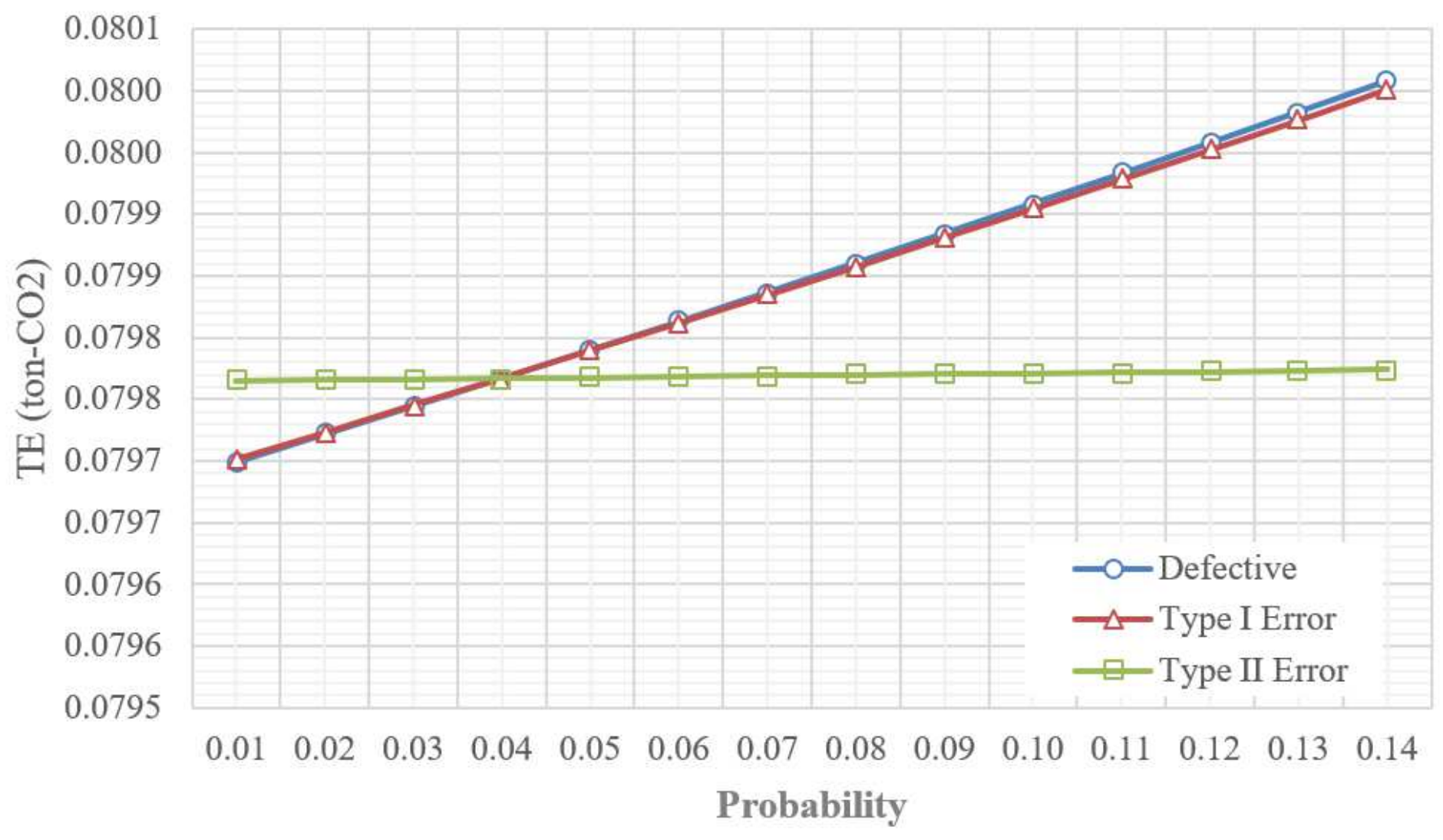

\section{Figure 4}

Sensitivity analysis of the probability of defective, type I error, and type II error on the TE (ton-CO2) 


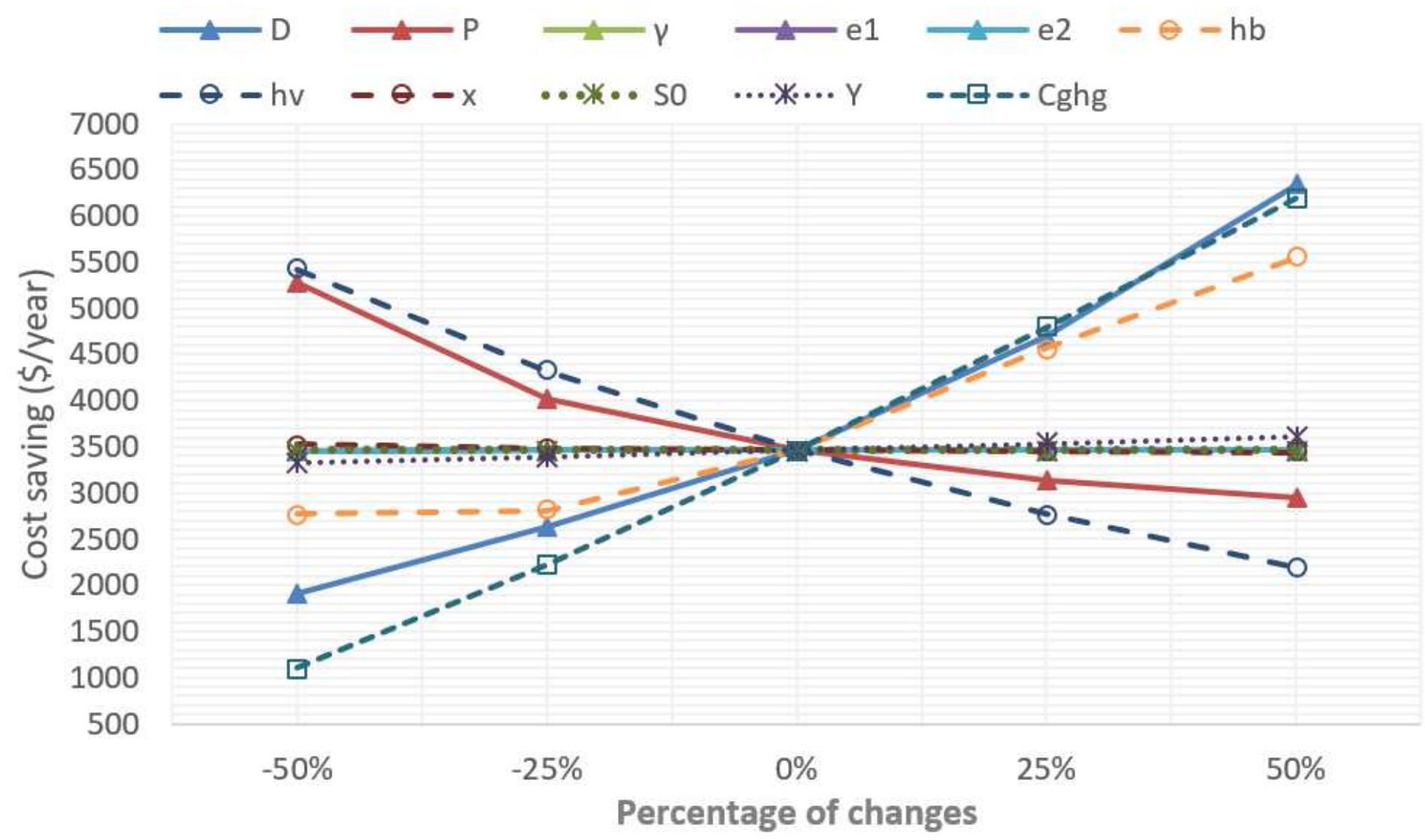

Figure 5

Sensitivity analysis $D, P, \beta, \delta, \rho, h \_b, h \_v, x, S \_0, Y$, and $C_{-} g h g$, on cost-saving with compared the independent optimal policy to the integrated optimal policy.

\section{Supplementary Files}

This is a list of supplementary files associated with this preprint. Click to download.

- GraphicalAbstract.docx 